\title{
The Case of "Rosa": Exploring Socio-Cultural Identities in Treatment
}

\section{RAYMOND RODRIGUEZ ${ }^{\mathrm{a}, \mathrm{b}}$}

\author{
${ }^{a}$ Aldea Counseling Services, New York, NY \\ ${ }^{\mathrm{b}}$ Correspondence regarding this article should be sent to Raymond Rodriguez, Aldea Counseling Services, \\ 601 West 150th Street, New York, NY 10031 \\ Email: rrodriguez@ aldeacounseling.com
}

\begin{abstract}
This paper explores social-cultural identities, in particular language, as an integral component in culturally competent psychotherapy. Integrating in treatment discussions around the complex matrix of intersecting socio-cultural identities between client and therapist enhances the therapeutic relationship and promotes treatment gains. Trauma processing, in particular, is enriched when issues of power and privilege as they pertain to socio-cultural identities are addressed. Using bilingualism and language switching in treatment are described as therapeutic interventions in working with clients who share a common language with the therapist. The importance of addressing race-based oppression and trauma is also noted.
\end{abstract}

Key Words: socio-cultural identity; therapist's social locations; race-based trauma; racial oppression; case study; clinical case study

I was delighted to read Vigoda Gonzales's (2018) in-depth discussion of her AEDP work with her client Rosa. I was particularly impressed with how the linguistic needs of the client played an important role in the treatment. As an Afro-Latino bilingual (Spanish/English) clinical social worker working with Spanish speaking and bilingual clients for the past fifteen years, I resonate deeply with the importance of language in treatment. I too have worked with many clients like Rosa, who benefited from adaptations to treatment that incorporate sociocultural considerations, including linguistic needs. I have witnessed in my practice and in my personal life how early experiences, traumatic or not, are encoded in the language in which they occurred; as a rule, these experiences are richer when they are explored in the language of origin. As with Rosa, I have noticed clients struggle with accessing early trauma memories in a second language, or conversely, distancing themselves from traumatic material through using a second language.

I was also particularly curious about the socio-cultural formulation of race in Rosa's treatment. From the case study, it seemed that racial discrimination and oppression played a pivotal role in Rosa's early relational trauma experiences with her immediate family. Though bilingualism was explored in detail, beyond a few references, I couldn't locate in the case study an exploration of racial oppression and trauma. I pondered how race and other socio-cultural identities, for both therapist and client, came up in treatment and were dealt with. 
In the comments below, I will explore language as a socio-cultural identity and how, as with Rosa, bringing language adaptations into therapy deepens treatment and enhances trauma processing. I will also explore race as a socio-cultural identity that deserves much attention in treatment, especially when working with people of color and other traditionally marginalized identities.

\section{LANGUAGE AS A SOCIOCULTURAL IDENTITY}

A sociocultural identity (or social identity or social location, all terms I use interchangeably) is defined in the literature as the groups people belong to because of their place or position in society and history (Kirk and Okazawa-Rey, 2013). We all inhabit multiple social identities at any given time. The social identities, or locations, we are most familiar with include categories like race, gender, sexual orientation, age, ethnicity, socio-economic status, physical/emotional-regulation ability, and religion. Language is also a social identity (Gumperz and Cook-Gumperz, 1982).

Language, as with any other social identity, expresses itself as a place of privilege or oppression in a particular place and time in history. A person's social identity will add to their experience of belonging, feeling understood, having a sense of agency and mastery, or, conversely, being excluded, rejected, or misunderstood. It is evident from the case discussion that, for Rosa, being able to express herself bilingually significantly shifted the therapeutic alliance which in turn supported the trauma processing of her early childhood experiences encoded in her first language. I too have noticed a strengthening of the therapeutic alliance with clients who speak Spanish when we engage in bilingualism in the office. In my experience, clients will more readily begin trauma processing when a strong therapeutic alliance has been solidly established. An express appreciation and invitation for exploration in treatment of the client's multiple social identities, including language, will support the deepening of the therapeutic alliance. In my office, clients have expressed feeling validated, understood, and safe when in the presence of someone who can understand their bilingual experience without their having to translate or further explain themselves.

\section{SHARING THE SOCIOCULTURAL IDENTITY OF LANGUAGE}

For Rosa, as for many of my clients, the sociocultural identity of language became a shared experience for both client and therapist. Particularly in trauma processing, where we invite clients to revisit deeply wounding experiences, being able to share such material in the language in which the experience was encoded seems to me to allow for a deeper and richer right-brain-mediated experience (Hill, 2015); such a right brain-mediated experience is more organic and developmental at its core. The co-created and co-regulatory therapeutic experience between therapist and client is enhanced by their shared language. When a client has to translate in order for a therapist to understand their processing, the client engages in a descriptive narration of an event, which is a more left-brain-mediated process (Hill, 2015); in some cases, the relational right-brain experience that is a key component for the processing gets lost in translation, so to speak. 
I observed this phenomenon with a French-speaking client while conducting Eye Movement Desensitization and Reprocessing (EMDR) therapy sessions with her: at different intervals, it was important for the client to process directly in French, her language of origin, and then, later in the session, to translate for me, her non-French speaking therapist, what had been happening. Though the client was able to process through a significant amount of material and we navigated together the complexities of both trauma-processing and translation, we observed the challenges that translation posed for the therapy, namely, the toll it took on the client's felt sense of being understood in her processing as it was happening in her language of origin. During moments of translating, the processing was inevitably suspended while I, her therapist, was made aware of what had come up. Needless to say, this processing followed by translation, added more time to the EMDR treatment.

\section{BILINGUALISM AND LANGUAGE SWITCHING AS ENHANCEMENTS TO TREATMENT}

I suspect that in Rosa's treatment, the fluidity of switching between two languages was yet another invaluable component. Bilingualism is not just a linguistic experience, but also a sociocultural one as well. As a bilingual person, I exist in two different sociocultural spheres that often do not intersect yet do enrich one another. In my office, I make a point of being transparent about my own bilingualism: early on in treatment I will inquire about the client's language experience, in particular with clients who speak more than one language. I openly invite into the therapy the client's bilingual experience, even when their language is unfamiliar to me.

Throughout treatment, I will refer to their language of origin with curiosity. I may inquire "How do you say that in (client's language of origin)?" "If you were to say that in (client's language of origin), how would it feel different to you?" "Can you say the same thing in (client's language of origin) and notice what is different this time?" This curiosity and open invitation around language is especially important for clients that have experienced discrimination and oppression, and for linguistic minorities.

With clients where we are both bilingual in English and Spanish, I will often use bilingualism therapeutically in session, much like Vigoda-Gonzalez did with Rosa. For instance, a common phrase I utilize in the somatically-oriented treatment I practice is "notice that" (Ogden and Fisher, 2015); there isn't an equivalent term in Spanish that carries the same meaning or intention. When I work with bilingual clients, it has been very helpful to say to the client "notice that" in English, even in the middle of a conversation that is predominantly in Spanish. Similarly, in Spanish we have "amor" and "cariño," two very distinct terms in Spanish that in English are subsumed under "love." When working with bilingual clients, I may draw from the Spanish distinctions of "love" to more clearly understand the meaning of the relational experience for that client. I can't recall a single bilingual client with whom I have worked who didn't appreciate the fluidity of language-switching in sessions. In fact, much like Rosa, these clients report feeling that they are much more at ease, that they could be more fully themselves, that they could open up more, and that they could share in session from an intimately emotional place in comparison to other monolingual therapy experiences. In reading the case study, it seemed that Rosa's ability to switch languages in her sessions with Vigoda-Gonzalez promoted a resonance in the therapeutic relationship and a deepening of the therapeutic process. 


\section{THE LIMITS OF ETHNIC MATCHING}

Like Vigoda Gonzalez, I don't believe in ethnic matching; and as she reports, nor does empirical research support it. It would be naive to propose that every client be seen by someone who could speak their language of origin. However, I argue that it is imperative for therapists to consider the treatment implications of the absence of the client's language of origin in sessions, and more broadly, the treatment implications of the socio-cultural differences between therapist and client.

A good example is a Chinese client I am currently seeing who is an English-language learner and who struggles mightily with being understood. This client often feels invisible in her current life in the U.S., similar to how Rosa felt in her childhood because of her race. In the U.S., my client has experienced a lot of discrimination because of her ethnicity and lack of English proficiency, despite her high level of education. She has had many personal and professional experiences where she has been devalued, ridiculed, and ostracized because of her poor use of English. She struggles with asserting herself in social and professional situations.

In treatment with this client, we have been deliberate in integrating ways where we both can slow down the process to ascertain understanding on either part so as to not replicate her experiences of feeling misunderstood and of oppression. Language differences, as well as other social identities, are front and center in our work. We each will repeatedly ask clarifying questions such as "Did I get that right?", "Did that make sense?", "Did I hear you correctly?", and "Do you mean...?" These clarifying questions are an agreed upon part of our treatment: they help secure and preserve safety and trust in the therapeutic process and in the therapeutic relationship. With these questions, and through these questions, we track understanding and convey the message that we each deeply value what the other says. These questions provide the basis for a corrective, co-regulatory experience of being heard, seen, understood, valued, and most importantly, a way of being present with the ever-shifting co-created and co-regulated, moment-to-moment experience.

As an English language learner, my Chinese client, unlike Rosa, struggles with expressing herself and with her social identities, in a completely different socio-cultural landscape, where language plays a pivotal part in her experience of oppression. We have spent many sessions exploring and contextualizing her socio-cultural identities and her experience of self in relation to others, as well as her experience of how others see her and interact with her. For this client, our commitment to paying close attention and having an appreciation for our socio-cultural and linguistic differences is reparative to her experience of invisibility; it also powerfully contributes to building her capacity to assert herself.

\section{WORKING WITH THE COMPLEX MATRIX OF SOCIOCULTURAL IDENTITIES}

In my clinical work, I endeavor to explore in depth a client's complex matrix of social identities and how these identities intersect. I spend time in sessions tracing places of stress and trauma due to those social identities. A quote that anchors this complexity for me and that I keep close to me in my heart and mind comes from Laura Brown's article Cultural Competence 
(Brown, 2009). In Brown's treatment of a Native American woman, her client says to her, "If you pretend not to see my color, then you don't see me, and for sure you don't see how I see you." It is my belief that, in this quote, we can substitute the word "color" with any other sociocultural identity to amplify a specific aspect of a client's life, including language.

Language is a social identity where a person may experience discrimination and oppression, or privilege and power. Having an accent or speaking in a way that deviates from what is considered Standard English, such as with Spanglish or African-American English, can bring about discrimination and ridicule in certain social and/or professional circles. I remember many painful moments in work settings when I was learning English where I was ridiculed and perceived as less intelligent because I couldn't fully express myself in Standard English.

\section{THE ROLE OF RACE AND RACIAL OPPRESSION IN TREATMENT}

As I mentioned above, in the case of Rosa, I was left wondering about a formulation of race and racial oppression in her treatment. The case study suggests race as a primary reason for the abuse Rosa suffered at the hand of her immediate caregivers. Though the therapist chose to explore the social identity of language as it played out in treatment, there is silence in the case study around race-based trauma in Rosa's childhood. Race is indeed a pivotal sociocultural identity, one with very significant implications for Rosa's early life experiences, and I believe, also for treatment.

Rosa's early life was marked by paternal alcoholism and domestic violence, but also by bullying, humiliation, and rejection for being different. Rosa is described as having "darker skin tone and coarser hair" that led to Rosa growing up feeling "invisible." It appears from the case study that Rosa's abuse at the hands of her mother and siblings had a lot to do with colorism (Knight, 2015), i.e., being phenotypically darker skin than her siblings. Presumably, Rosa's darker skin tone set her apart from her siblings and created a disadvantage that was met with abuse and rejection. In Spanish-speaking Caribbean countries, as in many other parts of the world, a lighter skin tone affords the person a great deal privilege. Conversely a darker skin tone frequently leads to discriminatory experiences. As with Rosa, discriminatory experiences based on darker skin tone can cumulatively create stress and even trauma.

In reading the case study I wondered if race and the trauma of racial discrimination were addressed in Vigoda Gonzales' treatment. And, if race was not addressed in the treatment, I wonder if in some way the silence around this social identity colluded with the client's childhood trauma around her race. Questions that have stayed with me in reading the case include: How much darker was Rosa in comparison to her family members? What messages did Rosa receive growing up about being different because of her darker skin tone? Were there explicit or implicit messages of devaluation around her darker skin tone? What limiting beliefs, if any, were created around racial inferiority? Are these beliefs still active and how do they impact Rosa now? How do they hold Rosa back from being her full self?

Analogous to this exploration, I also wonder about racial differences, if any, between the therapist and client. As Laura Brown's client suggests above, did the therapist really "see" Rosa's race and was she able to attune to her struggles with racial trauma? Or did the therapist 
inadvertently participate in the same silence that pervaded Rosa's early life? On the other hand, if they shared a racial identity, how was this addressed? Did the therapist and client spend time unpacking their similarities and how these may foster or hinder treatment? Were there implicit and explicit socio-cultural factors that were assumed because of shared socio-cultural and linguistic backgrounds? And if so, why were these similarities not addressed?

\section{THE IMPORTANCE OF OPENING UP SPACE FOR THERAPEUTIC CONVERSATIONS ABOUT SOCIOCULTURAL IDENTITIES}

I find it critical that, in the consulting room, we open up space to have conversation about sociocultural identities, language and race being two such variables. As with Rosa, inviting an exploration of language opens up a space for deepening the therapeutic relationship and propels trauma processing. We cannot extricate our social identities from the narrative of our lives. We are made up of our social identities, we experience the world through the lens of our identities, and the world interacts with us through the very same lens. The narrative of our lives and every single one of our life experiences, traumatic or not, are intertwined with our social identities. Expanding our psychotherapeutic frame with an open-ended invitation to our social identities to become an integral part of the therapeutic process can only but enrich the therapy process, as was the case with Rosa.

\section{WHAT I LEARNED ABOUT AEDP FROM THE CASE OF ROSA}

As a Sensorimotor Psychotherapy (SP) and Eye Movement Desensitization and Reprocessing (EMDR) therapist, with little familiarity with AEDP, I was struck with the remarkable similarity between Rosa's AEDP treatment, on the one hand, and SP and EMDR therapy, on the other. Some of the elements I found congruent in all three therapies include: the centrality of the therapeutic relationship as a place where clients can experience safety and trust; the moment-to-moment tracking of affective experiences in session; the preponderance of coregulatory experience between therapist and client, helping clients learn self-regulation; the focused attention to the moment-to-moment experience unfolding in the session; the aim of helping clients move past defenses and into core affect; and the processing of traumatic memories through re-experiencing past experiences without feeling overwhelmed. Different from EMDR, where processing occurs at a much faster speed, I appreciate AEDP's and SP's slowing down the process as a tool of deepening the moment-to-moment affective experience.

In reading the case of Rosa, I also learned new terminology that was unfamiliar to me. I particularly appreciated descriptive terms such as " the caregiver's errors of omission and commission," "feeling but not dealing," and "receptive affective experience." These terms explain client experiences that I see in my office every day in new language, so to speak!

\section{REFERENCES}

Brown, L. (2009). Cultural competence. In C. Courtois \& J.D. Ford (Eds.). Treating complex traumatic stress disorder (pp. 166-182). New York, NY: The Guildford Press. 
Gumperz, J.J, and Cook-Gumperz, J. (1982). Introduction: language and the communication of social identity. In Gumperz, J. (Ed.), Language and Social Identity (pp. 1-21). Cambridge, United Kingdom: Cambridge University Press.

Hill, D. (2015). Affect Regulation Theory: A Clinical Model. New York, NY: W.W. Norton \& Company, Inc.

Kirk, G. and Okazawa-Rey, M. (2013). Identities and Social Locations. Who am I Who are my people? In Adams, M., Blumenfeld, W.J. Castaneda, C., Hackman, H.W., Peters, M.L. \& Zuniga, X. (Eds.), Readings for Diversity and Social Justice, $3^{\text {rd }}$ edition (pp. 9-15). New York, NY: Taylor and Francis.

Knight, D. (2015). What's Colorism? In Teaching Tolerance. Retrieved from https://www.tolerance.org/magazine/fall-2015/whats-colorism

Ogden, P. and Fisher, J. (2015). Sensorimotor psychotherapy: Interventions for trauma and attachment. New York, NY: W.W. Norton \& Company, Inc.

Vigoda Gonzales, N. (2018). The merits of integrating accelerated experiential dynamic psychotherapy and cultural competence strategies in the treatment of relational trauma: The case of "Rosa. Pragmatic Case Studies in Psychotherapy, 14(1), Article 1, 1-57. Available: http://pcsp.libraries.rutgers.edu. http://dx.doi.org/10.14713/pcsp.v14i1.2032 